\title{
El programa de imágenes visuales del entorno en la producción de textos poéticos
}

\section{The program of visual images of the environment in the production of poetic texts}

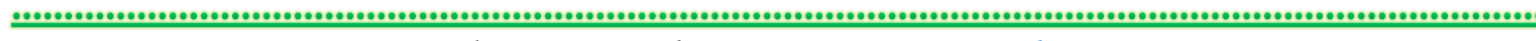 \\ Wilmer Ortega Chávez.awortegac@unia.edu.com \\ Orcid: https://orcid.org/0000-0002-5888-2902 \\ Annie Hellen Moreno Modesto ${ }^{b}$ hellenm_20@hotmail.com \\ Liliam Carola Zevallos Solis ${ }^{c}$ Izevalloss@unia.edu.com \\ Orcid: https://orcid.org/0000-0002-5531-1522 \\ a Universidad Nacional Intercultural de la Amazonia - Ucayali, Perú \\ b Universidad Nacional Hemilio Valdizán - Huánuco, Perú \\ c Universidad Nacional Intercultural de la Amazonia - Ucayali, Perú
}

Recibido: Septiembre/ 06/2020 •Aceptado: Octubre/02/2020 •Publicado: Diciembre/20/2020

RESUMEN

El problema que más ha preocupado en los distintos niveles educativos de nuestro entorno regional es la producción de textos resultado de ello nos propusimos el problema ¿Cuál es el efecto del programa uso de imágenes visuales del entorno en la producción de textos poéticos en estudiantes del segundo grado de educación secundaria de la Institución Educativa "Nuestra Señora de las Mercedes" de Huánuco?, cuyo objetivo general fue: Demostrar el efecto del Programa uso de imágenes visuales del entorno en la producción de textos poéticos. Siendo la hipótesis "El Programa uso de imágenes visuales del entorno mejora la producción de textos poéticos en los estudiantes del primer grado de educación secundaria de la Institución Educativa "Nuestra Señora de las Mercedes" de Huánuco". En cuanto a la metodología de estudio, se utilizó el método científico y como método específico el analítico con un diseño experimental se realizó el trabajo con una muestra aleatoria de 41 estudiantes un grupo control y otro experimental (muestra), obteniendo los resultados siguientes: donde se tiene que en la preprueba el $63,2 \%$ se ubica en el nivel C, y $36,8 \%$ se ubican en el nivel B, de la misma forma tenemos que en la postprueba el $68,4 \%$ se ubican en el nivel B y $31,6 \%$ en el nivel $A$. y el promedio en preprueba $(1,4)$ se diferencia con postprueba $(2,3)$. Se tiene una diferencia considerable entre preprueba y postprueba en cuanto al nivel de consistencia e integración textual en estudiantes del grupo experimental, lo que se justifica como efecto de la aplicación del Programa imágenes visuales del entorno.

Palabras clave: Imágenes visuales, textos poéticos, caligrafía, ortografía, etc.

${ }^{\mathrm{a}}$ Wilmer Ortega Chávez, ${ }^{\mathrm{b}}$ Annie Hellen Moreno Modesto y ${ }^{\mathrm{c}}$ Liliam Carola Zevallos Solis Articulo Protegido por Licencia Creative Commons: BY-NC-ND / Protected by Creative Commons: BY-NC-ND. Kolpa es una revista de acceso abierto / Kolpa is an Open Access Journal. 


\section{ABSTRACT}

The problem that has most concerned at the different educational levels of our regional environment is the production of texts. As a result, we set ourselves the problem: What is the effect of the program use of visual images of the environment in the production of poetic texts in students of the second Secondary education degree from the Educational Institution "Nuestra Señora de las Mercedes" of Huánuco? whose general objective was: To demonstrate the effect of the Program use of visual images of the environment in the production of poetic texts. Being the hypothesis "The program use of visual images of the environment improves the production of poetic texts in the students of the first grade of secondary education of the Educational Institution" Our Lady of the Mercedes "of Huánuco". Regarding the study methodology, the scientific method was used and the analytical one as a specific method with an experimental design, the work was carried out with a random sample of 41 students, a control group and an experimental group (sample), obtaining the following results: where we have that in the pre-test $63.2 \%$ are located at level $\mathrm{C}$, and $36.8 \%$ are located at level $\mathrm{B}$, in the same way we have that in the post-test $68.4 \%$ are located at level $B$ and $31.6 \%$ at level A. and the average in pre-test (1.4) differs with post-test (2.3). There is a considerable difference between pre-test and post-test in terms of the level of consistency and textual integration in students of the experimental group, which is justified as an effect of the application of the program visual images of the environment.

Key Words: Visual images, poems, calligraphy, spelling, etc.

\section{INTRODUCCIÓN}

La razón por la que se realizó la investigación fue profundizar el conocimiento teórico científico y, así, mejorar la práctica pedagógica implementando estrategias creativas que permitan lograr con efectividad los aprendizajes esperados.

La hipótesis general fue:

El Programa uso de imágenes visuales del entorno mejora la producción de textos poéticos en los estudiantes del segundo grado de educación secundaria de la Institución Educativa "Nuestra Señora de las Mercedes" de Huánuco.

Los objetivos del estudio fueron demostrar el efecto del Programa uso de imágenes visuales del entorno en la producción de textos poéticos, en específico en las dimensiones

${ }^{\mathrm{a}}$ Wilmer Ortega Chávez, ${ }^{\mathrm{b}}$ Annie Hellen Moreno Modesto y ${ }^{\mathrm{c}}$ Liliam Carola Zevallos Solis Articulo Protegido por Licencia Creative Commons: BY-NC-ND / Protected by Creative Commons: BY-NC-ND.

Kolpa es una revista de acceso abierto / Kolpa is an Open Access Journal. 
consistencia e interpretación textual, organización textual, nivel lexical, expresividad, relación morfosintáctica, ortografía y caligrafía.

Los autores que contribuyeron con sus resultados es considerado a Clemente, (2006), en su tesis "Producción de textos escritos en quechua como lengua número 01. Desafío de profesores y alumnos en la unidad educativa "ETB" Río Blanco. Área Rural". Cochabamba. Bolivia, tesis para optar el grado de magíster en Educación Intercultural Bilingüe llego a las siguientes conclusiones; Los alumnos del habla quechua o aimara demuestran dificultades en la producción de textos escritos, que los textos verbales. Los docentes carecen de metodología adecuada para la producción de los textos escritos por los alumnos quechua hablantes. Los docentes demuestran dificultades para comprender la producción verbal de los textos por los alumnos, así mismo, carecen de la implementación del vocabulario en lengua aborigen.

Rodríguez (2005), en su tesis titulada "Estrategias Metodológicas aplicada a la Producción de Textos escritos en los alumnos del IV ciclo $\left(3^{\circ}\right.$ y $\left.4^{\circ}\right)$ en educación primaria en el área de Comunicación Integral de las Instituciones Educativas de la UGEL 01". Universidad Femenina del Sagrado Corazón UNIFE. Lima del mismo modo llego a las siguientes conclusiones; Las estrategias más destacadas son de carácter audiovisual (72\%), y las de material manual (54\%), Los textos más preferidos por las alumnas son de carácter narrativo, y en segundo lugar los textos de carácter creativos, como los cuentos y mitos, No existe espacios ni tiempo adecuados para la producción de textos, en cierta manera es cierto, pero es necesario seguir investigando.

Gonzales (1996), con su planteamiento que es una representación visual, que manifiesta la apariencia de un objeto real o imaginario. Aunque el término suele entenderse como sinónimo de representación visual, también se aplica como extensión para otros tipos de percepción, como imágenes auditivas, olfativas, táctiles, kinestésicas, etcétera. Las imágenes que la persona no sabe y vive interiormente son denominadas imágenes mentales, mientras que se designan como imágenes creadas (o bien como imágenes reproducidas,

${ }^{\mathrm{a}}$ Wilmer Ortega Chávez, ${ }^{\mathrm{b}}$ Annie Hellen Moreno Modesto y ${ }^{\mathrm{c}}$ Liliam Carola Zevallos Solis Articulo Protegido por Licencia Creative Commons: BY-NC-ND / Protected by Creative Commons: BY-NC-ND. Kolpa es una revista de acceso abierto / Kolpa is an Open Access Journal. 
según el caso) las que representan visualmente un objeto mediante técnicas diferentes: dibujo, diseño, pintura, fotografía o vídeo, entre otras.

Barriga, (1998), considerando que el estudiante es un ser social activo, pensante, creativo, es decir una potencialidad como "persona", son válidos sus ideas e intereses, sus opiniones, necesidades y problemas.

\section{METODOLOGÍA}

El método fue deductivo y el enfoque cuantitativo; el diseño de investigación fue experimental puro, con la determinación de dos grupos: uno de control y otro experimental; se realizó 15 sesiones y trabajos con los estudiantes de manera demostrativa, sin embargo, hubo limitaciones por la inasistencia de algunos estudiantes, pero se superó y se logró resultados favorables como se demuestra en las conclusiones y resultados.

La población; estuvo conformada por los estudiantes del segundo grado de Educación Secundaria de la Institución Educativa "Nuestra Señora de las Mercedes" Huánuco, mientras la muestra la cual se seleccionó mediante el muestreo probabilístico, seleccionándose un grupo de control y un grupo experimental, así mismo la técnica e instrumento que se utilizó la encuesta; que fue de carácter autoevaluativo, referido a las razones de la elección de las imágenes del entorno y al desempeño de los educandos para la ejecución del proceso de elaboración de textos poéticos. El instrumento fue una lista de cotejo compuesta por 22 ítems. Para el análisis y procesamiento de datos se consideró el SPSS, Versión 23.

\section{RESULTADOS}

A través del uso del programa de imágenes visuales del entorno en dicho proceso también fue el propósito de contrastar los resultados del pre test con el post test para saber si ha habido logro o no en la producción textos poéticos, aplicando el uso del programa de

${ }^{\mathrm{a}}$ Wilmer Ortega Chávez, ${ }^{\mathrm{b}}$ Annie Hellen Moreno Modesto y ${ }^{\mathrm{c}}$ Liliam Carola Zevallos Solis Articulo Protegido por Licencia Creative Commons: BY-NC-ND / Protected by Creative Commons: BY-NC-ND. Kolpa es una revista de acceso abierto / Kolpa is an Open Access Journal. 
imágenes visuales del entorno que para su ejecución de la investigación se planifico 10 sesiones de 2 horas en diversos horarios consolidando en el siguiente resultado:

\section{Resultados de producción de textos poéticos en el grupo control}

\section{Tabla 1}

Nivel de Consistencia e integración textual

\begin{tabular}{|c|c|c|c|c|c|c|}
\hline \multirow{3}{*}{$\begin{array}{l}\text { Consistencia } \\
\text { e }\end{array}$} & \multirow{2}{*}{\multicolumn{2}{|c|}{ NIVEL }} & \multicolumn{4}{|c|}{ PREPRUEBA POSTPRUEBA } \\
\hline & & & fi & $\%$ & fi & $\%$ \\
\hline & A & 3 & 0 & 0.0 & 0 & 0.0 \\
\hline integracion & $\mathrm{B}$ & 2 & 11 & 50.0 & 13 & 59.1 \\
\hline & $\mathrm{C}$ & 1 & 11 & 50.0 & 9 & 40.9 \\
\hline Total & & & 22 & 100 & 22 & 100 \\
\hline Promed & & & 1.5 & & 1.6 & \\
\hline
\end{tabular}

Los resultados del nivel de consistencia e integración textual en estudiantes del grupo control en la tabla 1, donde se tiene que en la preprueba el $50 \%$ se ubica en el nivel C, y otro $50 \%$ se ubican en el nivel B, de la misma forma tenemos que en la postprueba el $40,9 \%$ se ubican en el nivel C y 59,1\% en el nivel B. Se tiene poca diferencia entre preprueba y postprueba en cuanto al nivel de consistencia e integración textual en estudiantes del grupo control y el promedio en preprueba $(1,5)$ es similar en postprueba $(1,6)$.

\section{Tabla 2}

Nivel de consistencia e integración textual

\begin{tabular}{|c|c|c|c|c|c|c|}
\hline \multirow{5}{*}{$\begin{array}{l}\text { Consistencia } \\
\text { e integración } \\
\text { textual }\end{array}$} & \multirow{2}{*}{\multicolumn{2}{|c|}{ NIVEL }} & \multicolumn{2}{|c|}{ PREPRUEBA } & \multicolumn{2}{|c|}{ POSTPRUEBA } \\
\hline & & & fi & $\%$ & fi & $\%$ \\
\hline & A & 3 & 0 & 0.0 & 6 & 31.6 \\
\hline & B & 2 & 7 & 36.8 & 13 & 68.4 \\
\hline & $\mathrm{C}$ & 1 & 12 & 63.2 & 0 & 0.0 \\
\hline $\begin{array}{r}\text { Total } \\
\text { Promed }\end{array}$ & & & $\begin{array}{l}19 \\
14\end{array}$ & 100.0 & $\begin{array}{l}19 \\
23\end{array}$ & 100 \\
\hline
\end{tabular}

${ }^{\mathrm{a}}$ Wilmer Ortega Chávez, ${ }^{\mathrm{b}}$ Annie Hellen Moreno Modesto y ${ }^{\mathrm{c}}$ Liliam Carola Zevallos Solis Articulo Protegido por Licencia Creative Commons: BY-NC-ND / Protected by Creative Commons: BY-NC-ND. Kolpa es una revista de acceso abierto / Kolpa is an Open Access Journal. 
Los resultados del nivel de consistencia e integración textual en estudiantes del grupo experimental en la tabla 2, donde se tiene que en la preprueba el 63,2\% se ubica en el nivel C, y $36,8 \%$ se ubican en el nivel B, de la misma forma tenemos que en la postprueba el 68,4\% se ubican en el nivel B y $31,6 \%$ en el nivel A. y el promedio en preprueba $(1,4)$ se diferencia con postprueba $(2,3)$. Se tiene una diferencia considerable entre preprueba y postprueba en cuanto al nivel de consistencia e integración textual en estudiantes del grupo experimental, lo que se justifica como efecto de la aplicación del Programa imágenes visuales del entorno.

\section{Tabla 3}

Nivel de Organización textual

\begin{tabular}{|c|c|c|c|c|c|c|}
\hline \multirow{4}{*}{$\begin{array}{l}\text { Organización } \\
\text { textual }\end{array}$} & \multirow{2}{*}{\multicolumn{2}{|c|}{ NIVEL }} & \multicolumn{2}{|c|}{ PREPRUEBA } & \multicolumn{2}{|c|}{ POSTPRUEBA } \\
\hline & & & $\mathrm{fi}$ & $\%$ & $\mathrm{Fi}$ & $\%$ \\
\hline & A & 3 & 0 & 0.0 & 0 & 0.0 \\
\hline & B & 2 & 17 & 77.3 & 16 & 72.7 \\
\hline & $\mathrm{C}$ & 1 & 5 & 22.7 & 6 & 27.3 \\
\hline Total & & & 22 & 100 & 22 & 100 \\
\hline Promed & & & 1.8 & & 1.7 & \\
\hline
\end{tabular}

Los resultados del nivel de organización textual en estudiantes del grupo control en la tabla 3, donde se tiene que en la preprueba el $22,7 \%$ se ubica en el nivel C, y 77,3\% se ubican en el nivel B, de la misma forma tenemos que en la postprueba el 27,3\% se ubican en el nivel C y 71,7\% en el nivel B. Se tiene poca diferencia entre preprueba y postprueba en estudiantes del grupo control y el promedio en preprueba $(1,8)$ es similar en postprueba $(1,7)$.

\section{Tabla 4}

Nivel de Nivel lexical

\begin{tabular}{|c|c|c|c|c|c|}
\hline \multirow{5}{*}{$\begin{array}{l}\text { Nivel } \\
\text { Lexical }\end{array}$} & \multirow{2}{*}{ NIVEL } & \multicolumn{4}{|c|}{ PREPRUEBA POSTPRUEBA } \\
\hline & & $\mathrm{fi}$ & $\%$ & $\mathrm{Fi}$ & $\%$ \\
\hline & A & 0 & 0.0 & 0 & 0.0 \\
\hline & B & 4 & 18.2 & 3 & 13.6 \\
\hline & C 1 & 18 & 81.8 & 19 & 86.4 \\
\hline & & 22 & 100 & 22 & 100 \\
\hline $\operatorname{Prc}$ & & 1.2 & & 1.1 & \\
\hline
\end{tabular}

${ }^{\mathrm{a}}$ Wilmer Ortega Chávez, ${ }^{\mathrm{b}}$ Annie Hellen Moreno Modesto y ${ }^{\mathrm{c}}$ Liliam Carola Zevallos Solis Articulo Protegido por Licencia Creative Commons: BY-NC-ND / Protected by Creative Commons: BY-NC-ND. Kolpa es una revista de acceso abierto / Kolpa is an Open Access Journal. 
Los resultados del nivel de nivel lexical en estudiantes del grupo control en la tabla 4, donde se tiene que en la preprueba el $81,8 \%$ se ubica en el nivel C, y $18,2 \%$ se ubican en el nivel B, de la misma forma tenemos que en la postprueba el 86,4\% se ubican en el nivel C y $13,6 \%$ en el nivel B. Se tiene poca diferencia entre preprueba y postprueba en cuanto al nivel de nivel lexical en estudiantes del grupo control y el promedio en preprueba $(1,2)$ es similar en postprueba $(1,1)$.

\section{Tabla 5}

Nivel de expresividad

\begin{tabular}{ccccccc}
\hline & \multirow{2}{*}{ NIVEL } & \multicolumn{3}{c}{ PREPRUEBA } & \multicolumn{2}{c}{ POSTPRUEBA } \\
\cline { 2 - 7 } Expresividad & fi & $\%$ & fi & $\%$ \\
\cline { 2 - 7 } & A & 3 & 1 & 4.5 & 2 & 9.1 \\
& B & 2 & 17 & 77.3 & 17 & 77.3 \\
& $\mathrm{C}$ & 1 & 4 & 18.2 & 3 & 13.6 \\
\hline Total & & 22 & 100 & 22 & 100 \\
Promedio & & 1.9 & & 2.0 & \\
\hline
\end{tabular}

Los resultados del nivel de expresividad en estudiantes del grupo control en la tabla 5, donde se tiene que en la preprueba el 18,2\% se ubica en el nivel C, 77,3\% en el nivel B y otro $4,5 \%$ se ubican en el nivel C, de la misma forma tenemos que en la postprueba el 13,6\% se ubican en el nivel C, 77,3\% en el nivel B y 9,1\% en el nivel A. Se tiene poca diferencia entre preprueba y postprueba en cuanto al nivel de expresividad en estudiantes del grupo control y el promedio en preprueba $(1,9)$ es similar en postprueba $(2,0)$.

\section{Tabla 6}

Nivel de Relaciones morfosintácticas

\begin{tabular}{|c|c|c|c|c|c|}
\hline \multirow{5}{*}{$\begin{array}{l}\text { Relaciones } \\
\text { morfosintácticas }\end{array}$} & \multirow{2}{*}{ NIVEL } & \multicolumn{4}{|c|}{ PREPRUEBA POSTPRUEBA } \\
\hline & & fi & $\%$ & $\mathrm{Fi}$ & $\%$ \\
\hline & A & 0 & 0.0 & 0 & 0.0 \\
\hline & B & 15 & 68.2 & 13 & 59.1 \\
\hline & $\mathrm{C}$ & 7 & 31.8 & 9 & 40.9 \\
\hline Total & & 22 & 100 & 22 & 100 \\
\hline Promedic & & 1.7 & & 1.6 & \\
\hline
\end{tabular}

${ }^{\mathrm{a}}$ Wilmer Ortega Chávez, ${ }^{\mathrm{b}}$ Annie Hellen Moreno Modesto y ${ }^{\mathrm{c}}$ Liliam Carola Zevallos Solis Articulo Protegido por Licencia Creative Commons: BY-NC-ND / Protected by Creative Commons: BY-NC-ND. Kolpa es una revista de acceso abierto / Kolpa is an Open Access Journal. 
Los resultados del nivel de relaciones morfosintácticas en estudiantes del grupo control en la tabla 6, donde se tiene que en la preprueba el 31,8\% se ubica en el nivel C, y $69,2 \%$ se ubican en el nivel B, de la misma forma tenemos que en la postprueba el $40,9 \%$ se ubican en el nivel C y 59,1\% en el nivel B. Se tiene poca diferencia entre preprueba y postprueba en cuanto al nivel de relaciones morfosintácticas en estudiantes del grupo control y el promedio en preprueba $(1,7)$ es similar en postprueba $(1,6)$.

\section{Tabla 7}

Nivel de ortografía

\begin{tabular}{|c|c|c|c|c|c|c|}
\hline \multirow{5}{*}{ Ortografía } & \multirow{2}{*}{\multicolumn{2}{|c|}{ NIVEL }} & \multicolumn{4}{|c|}{ PREPRUEBA POSTPRUEBA } \\
\hline & & & fi & $\%$ & $\mathrm{fi}$ & $\%$ \\
\hline & A & 3 & 0 & 0.0 & 0 & 0.0 \\
\hline & B & 2 & 2 & 9.1 & 6 & 27.3 \\
\hline & $\mathrm{C}$ & 1 & 20 & 90.9 & 16 & 72.7 \\
\hline & & & 22 & 100 & 22 & 100 \\
\hline Prome & dio & & 1.1 & & 1.3 & \\
\hline
\end{tabular}

Los resultados del nivel de ortografía en estudiantes del grupo control en la tabla $\mathrm{N}^{\circ}$ 7, donde se tiene que en la preprueba el 90,9\% se ubica en el nivel C, y 9,1\% se ubican en el nivel B, de la misma forma tenemos que en la postprueba el 72,2\% se ubican en el nivel C y $27,3 \%$ en el nivel B. Se tiene poca diferencia entre preprueba y postprueba en cuanto al nivel de ortografía en estudiantes del grupo.

\section{Tabla 8}

Nivel de caligrafía

\begin{tabular}{ccccccc}
\hline \multirow{3}{*}{ Caligrafía } & \multirow{2}{*}{ NIVEL } & \multicolumn{3}{l}{ PREPRUEBA } & \multicolumn{2}{l}{ POSTPRUEBA } \\
\cline { 2 - 7 } & & & $\mathrm{fi}$ & $\%$ & $\mathrm{Fi}$ & $\%$ \\
& $\mathrm{~A}$ & 2 & 14 & 63.6 & 15 & 68.2 \\
& $\mathrm{~B}$ & 1 & 8 & 36.4 & 7 & 31.8 \\
\hline Total & & 22 & 100.0 & 22 & 100.0 \\
Promedio & & 1.6 & & 1.7 & \\
\hline
\end{tabular}

${ }^{\mathrm{a}}$ Wilmer Ortega Chávez, ${ }^{\mathrm{b}}$ Annie Hellen Moreno Modesto y ${ }^{\mathrm{c}}$ Liliam Carola Zevallos Solis Articulo Protegido por Licencia Creative Commons: BY-NC-ND / Protected by Creative Commons: BY-NC-ND. Kolpa es una revista de acceso abierto / Kolpa is an Open Access Journal. 
Los resultados del nivel de caligrafía en estudiantes del grupo control en la tabla 8 , donde se tiene que en la preprueba el 36,4\% se ubica en el nivel B, y 63,6\% se ubican en el nivel A, de la misma forma tenemos que en la postprueba el 31,8\% se ubican en el nivel B y $68,2 \%$ en el nivel A. Se tiene poca diferencia entre preprueba y postprueba en cuanto al nivel de caligrafía en estudiantes del grupo control y el promedio en preprueba $(1,6)$ es similar en postprueba $(1,7)$.

\section{Resultados de producción de textos poéticos en el grupo experimental}

\section{Tabla 9}

Nivel de consistencia

\begin{tabular}{|c|c|c|c|c|c|c|}
\hline \multirow{5}{*}{$\begin{array}{l}\text { Consistencia } \\
\text { e } \\
\text { integración } \\
\text { textual }\end{array}$} & \multirow{2}{*}{\multicolumn{2}{|c|}{ NIVEL }} & \multicolumn{2}{|c|}{ PREPRUEBA } & \multicolumn{2}{|c|}{ POSTPRUEBA } \\
\hline & & & fi & $\%$ & $\mathrm{fi}$ & $\%$ \\
\hline & A & 3 & 0 & 0.0 & 6 & 31.6 \\
\hline & B & 2 & 7 & 36.8 & 13 & 68.4 \\
\hline & $\mathrm{C}$ & 1 & 12 & 63.2 & 0 & 0.0 \\
\hline \multicolumn{3}{|c|}{ Total } & 19 & 100.0 & 19 & 100 \\
\hline \multicolumn{3}{|c|}{ Promedio } & 1.4 & & 2.3 & \\
\hline
\end{tabular}

Los resultados del nivel de consistencia e integración textual en estudiantes del grupo experimental en la tabla 9, donde se tiene que en la preprueba el 63,2\% se ubica en el nivel C, y $36,8 \%$ se ubican en el nivel B, de la misma forma tenemos que en la postprueba el 68,4\% se ubican en el nivel B y $31,6 \%$ en el nivel A. y el promedio en preprueba $(1,4)$ se diferencia con postprueba $(2,3)$. Se tiene una diferencia considerable entre preprueba y postprueba en cuanto al nivel de consistencia e integración textual en estudiantes del grupo experimental, lo que se justifica como efecto de la aplicación del Programa imágenes visuales del entorno.

${ }^{\mathrm{a}}$ Wilmer Ortega Chávez, ${ }^{\mathrm{b}}$ Annie Hellen Moreno Modesto y ${ }^{\mathrm{c}}$ Liliam Carola Zevallos Solis Articulo Protegido por Licencia Creative Commons: BY-NC-ND / Protected by Creative Commons: BY-NC-ND. Kolpa es una revista de acceso abierto / Kolpa is an Open Access Journal. 
Tabla 10

Nivel de organización textual

\begin{tabular}{ccccccc}
\hline & \multirow{2}{*}{ NIVEL } & \multicolumn{3}{c}{ PREPRUEBA } & \multicolumn{3}{c}{ POSTPRUEBA } \\
\cline { 3 - 7 } Organización & & fi & $\%$ & fi & $\%$ \\
\cline { 3 - 7 } Textual: & A & 3 & 0 & 0.0 & 1 & 5.3 \\
& B & 2 & 10 & 52.6 & 18 & 94.7 \\
& $\mathrm{C}$ & 1 & 9 & 47.4 & 0 & 0.0 \\
\hline Total & & 19 & 100 & 19 & 100 \\
Promedio & & 1.5 & & 2.1 & \\
\hline
\end{tabular}

Los resultados del nivel de organización textual en estudiantes del grupo experimental en la tabla 10, donde se tiene que en la preprueba el 47,4\% se ubica en el nivel C, y 52,6\% se ubican en el nivel B, de la misma forma tenemos que en la postprueba el $94,7 \%$ se ubican en el nivel B y 5,3\% en el nivel A. y el promedio en preprueba $(1,5)$ se diferencia con postprueba $(2,1)$. Se tiene una diferencia considerable entre preprueba y postprueba en cuanto al nivel de organización textual en estudiantes del grupo experimental, lo que se justifica como efecto de la aplicación del Programa imágenes visuales del entorno.

\section{Tabla 11}

Nivel de Nivel lexical

\begin{tabular}{|c|c|c|c|c|c|c|}
\hline \multirow{4}{*}{$\frac{\text { Nivel }}{\text { Lexical: }}$} & \multirow{2}{*}{\multicolumn{2}{|c|}{ NIVEL }} & \multicolumn{4}{|c|}{ PREPRUEBA POSTPRUEBA } \\
\hline & & & fi & $\%$ & $\mathrm{fi}$ & $\%$ \\
\hline & $\mathbf{A}$ & 3 & 0 & 0.0 & 0 & 0.0 \\
\hline & B & 2 & 5 & 26.3 & 14 & 73.7 \\
\hline & $\mathbf{C}$ & 1 & 14 & 73.7 & 5 & 26.3 \\
\hline & & & 19 & 100 & 19 & 100 \\
\hline Pron & edio & & 1.3 & & 1.7 & \\
\hline
\end{tabular}

Los resultados del nivel lexical en estudiantes del grupo experimental en la tabla 11, donde se tiene que en la preprueba el $73,7 \%$ se ubica en el nivel C, y $26,3 \%$ se ubican en el nivel B, de la misma forma tenemos que en la postprueba el 26,3\% se ubican en el nivel C y $73,7 \%$ en el nivel B. y el promedio en preprueba $(1,3)$ se diferencia con postprueba $(1,7)$. Se

${ }^{\mathrm{a}}$ Wilmer Ortega Chávez, ${ }^{\mathrm{b}}$ Annie Hellen Moreno Modesto y ${ }^{\mathrm{c}}$ Liliam Carola Zevallos Solis Articulo Protegido por Licencia Creative Commons: BY-NC-ND / Protected by Creative Commons: BY-NC-ND. Kolpa es una revista de acceso abierto / Kolpa is an Open Access Journal. 
tiene una diferencia considerable entre preprueba y postprueba en cuanto al nivel de consistencia e integración textual en estudiantes del grupo experimental, lo que se justifica como efecto de la aplicación del Programa imágenes visuales del entorno.

\section{Tabla 12}

Nivel de expresividad

\begin{tabular}{|c|c|c|c|c|c|c|}
\hline \multirow{5}{*}{ Expresividad } & \multirow{2}{*}{\multicolumn{2}{|c|}{ NIVEL }} & \multicolumn{2}{|c|}{ PREPRUEBA } & \multicolumn{2}{|c|}{ POSTPRUEBA } \\
\hline & & & fi & $\%$ & fi & $\%$ \\
\hline & A & 3 & 0 & 0.0 & 15 & 78.9 \\
\hline & B & 2 & 15 & 78.9 & 4 & 21.1 \\
\hline & $\mathrm{C}$ & 1 & 4 & 21.1 & 0 & 0.0 \\
\hline Total & & & 19 & 100 & 19 & 100 \\
\hline Promed & & & 1.8 & & 2.8 & \\
\hline
\end{tabular}

Los resultados del nivel expresividad en estudiantes del grupo experimental en la tabla 12, donde se tiene que en la preprueba el $21,1 \%$ se ubica en el nivel C, y 78,9\% se ubican en el nivel B, de la misma forma tenemos que en la postprueba el 21,1\% se ubican en el nivel B y $78,9 \%$ en el nivel A. y el promedio en preprueba $(1,8)$ se diferencia con postprueba $(2,8)$.Se tiene una diferencia considerable entre preprueba y postprueba en cuanto al nivel de expresividad en estudiantes del grupo experimental, lo que se justifica como efecto de la aplicación del Programa imágenes visuales del entorno.

\section{Tabla 13}

Nivel de Relaciones morfosintácticas

\begin{tabular}{lcccccc}
\hline & \multirow{2}{*}{ NIVEL } & \multicolumn{3}{c}{ PREPRUEBA } & \multicolumn{2}{c}{ POSTPRUEBA } \\
\cline { 2 - 7 } Relaciones & & & fi & $\%$ & fi & $\%$ \\
morfosintácticas & A & 3 & 0 & 0.0 & 3 & 15.8 \\
& B & 2 & 15 & 78.9 & 16 & 84.2 \\
& C & 1 & 4 & 21.1 & 0 & 0.0 \\
\hline Total & & & 19 & 100 & 19 & 100 \\
Promedio & & 1.8 & & 2.2 & \\
\hline
\end{tabular}

Los resultados del nivel de relaciones morfosintácticas en estudiantes del grupo experimental en la tabla 13, donde se tiene que en la preprueba el $21,1 \%$ se ubica en el nivel

${ }^{\mathrm{a}}$ Wilmer Ortega Chávez, ${ }^{\mathrm{b}}$ Annie Hellen Moreno Modesto y ${ }^{\mathrm{c}}$ Liliam Carola Zevallos Solis Articulo Protegido por Licencia Creative Commons: BY-NC-ND / Protected by Creative Commons: BY-NC-ND. Kolpa es una revista de acceso abierto / Kolpa is an Open Access Journal. 
C, y 78,9\% se ubican en el nivel B, de la misma forma tenemos que en la postprueba el 84,2\% se ubican en el nivel B y $15,8 \%$ en el nivel A. y el promedio en preprueba $(1,8)$ se diferencia con postprueba $(2,2)$. Se tiene una diferencia considerable entre preprueba y postprueba en cuanto al nivel de consistencia e integración textual en estudiantes del grupo experimental, lo que se justifica como efecto de la aplicación del Programa imágenes visuales del entorno.

\section{Tabla 14}

Nivel de ortografía

\begin{tabular}{|c|c|c|c|c|c|c|}
\hline \multirow{5}{*}{ Ortografía } & \multirow{2}{*}{\multicolumn{2}{|c|}{ NIVEL }} & \multicolumn{2}{|c|}{ PREPRUEBA } & \multicolumn{2}{|c|}{ POSTPRUEBA } \\
\hline & & & fi & $\%$ & fi & $\%$ \\
\hline & A & 3 & 0 & 0.0 & 1 & 5.3 \\
\hline & B & 2 & 4 & 21.1 & 17 & 89.5 \\
\hline & $\mathrm{C}$ & 1 & 15 & 78.9 & 1 & 5.3 \\
\hline Tot & & & 19 & 100 & 19 & 100 \\
\hline Prom & & & 1.2 & & 2.0 & \\
\hline
\end{tabular}

Los resultados del nivel de ortografía en estudiantes del grupo experimental en la tabla 14, donde se tiene que en la preprueba el 78,9\% se ubica en el nivel C, y $21,1 \%$ se ubican en el nivel B, de la misma forma tenemos que en la postprueba el 89,5\% se ubican en el nivel B y $5,3 \%$ en el nivel A. y el promedio en preprueba $(1,2)$ se diferencia con postprueba $(2,0)$. Se tiene una diferencia considerable entre preprueba y postprueba en estudiantes del grupo experimental, lo que se justifica como efecto de la aplicación del Programa imágenes visuales del entorno.

Tabla 15

Nivel de caligrafía

\begin{tabular}{|c|c|c|c|c|c|c|}
\hline \multirow{4}{*}{ Caligrafía } & \multirow{2}{*}{\multicolumn{2}{|c|}{ NIVEL }} & \multicolumn{2}{|c|}{ PREPRUEBA } & \multicolumn{2}{|c|}{ POSTPRUEBA } \\
\hline & & & $\mathrm{fi}$ & $\%$ & fi & $\%$ \\
\hline & A & 2 & 17 & 89.5 & 19 & 100.0 \\
\hline & B & 1 & 2 & 10.5 & 0 & 0.0 \\
\hline \multicolumn{3}{|c|}{ Total } & 19 & 100.0 & 19 & 100.0 \\
\hline \multicolumn{3}{|c|}{ Promedio } & 1.9 & & 2.0 & \\
\hline
\end{tabular}

${ }^{\mathrm{a}}$ Wilmer Ortega Chávez, ${ }^{\mathrm{b}}$ Annie Hellen Moreno Modesto y ${ }^{\mathrm{c}}$ Liliam Carola Zevallos Solis Articulo Protegido por Licencia Creative Commons: BY-NC-ND / Protected by Creative Commons: BY-NC-ND. Kolpa es una revista de acceso abierto / Kolpa is an Open Access Journal. 
Los resultados del nivel de caligrafía en estudiantes del grupo experimental en la tabla 15, donde se tiene que en la preprueba el 10,5\% se ubica en el nivel B, y 89,5\% se ubican en el nivel A, de la misma forma tenemos que en la postprueba el 100\% se ubican en el nivel A. y el promedio en preprueba $(1,9)$ es similar en postprueba $(2,0)$. Se tiene una diferencia considerable entre preprueba y postprueba en cuanto al nivel de caligrafía en estudiantes del grupo experimental, lo que se justifica como efecto de la aplicación del Programa imágenes visuales del entorno.

\section{DISCUSIÓN}

El propósito fundamental de esta investigación fue demostrar el efecto del Programa uso de imágenes visuales del entorno en la producción de textos poéticos en estudiantes del segundo grado de educación secundaria de la Institución Educativa "Nuestra Señora de las Mercedes" de Huánuco Proceso por el cual se ha tratado de determinar la validez del programa como estudio experimental.

Para poder contrastar nuestro marco teórico y la hipótesis es necesario tener en cuenta nuestros resultados con las concepciones planteadas de cada uno de ellos e interpretar y reflexionar sobre ello. Es preciso comenzar analizando los datos que se obtuvieron en el grupo antes del Programa uso de imágenes visuales del entorno en la producción de textos poéticos en estudiantes del segundo grado; Los resultados que se obtuvieron en el pre prueba y post prueba en promedios aritméticos de cada nivel de la producción de textos poéticos de la ficha de progresión de desempeño que implica un logro significativo en el grupo experimental precisamente en cierta diferencia mínima, vale decir que la mayoría de los estudiantes del grupo experimental, si hacen uso del programa de imágenes visuales del entorno en la producción de textos poéticos como estrategia de aprendizaje.

(María Elena Camba) En la sociedad actual, dominada por las imágenes y signos icónicos surgen interrogantes sobre la eficacia de la imagen junto a la palabra en la comunicación.

${ }^{\mathrm{a}}$ Wilmer Ortega Chávez, ${ }^{\mathrm{b}}$ Annie Hellen Moreno Modesto y ${ }^{\mathrm{c}}$ Liliam Carola Zevallos Solis Articulo Protegido por Licencia Creative Commons: BY-NC-ND / Protected by Creative Commons: BY-NC-ND. Kolpa es una revista de acceso abierto / Kolpa is an Open Access Journal. 
"Una imagen vale más que mil palabras". Los chicos sienten el poder sugestivo con las imágenes de luces y colores.

Es común asociar la visión de un hecho con su existencia, o sea la imagen con la realidad. Sin embargo, las imágenes son siempre signos de algo ajeno que incorporan diversos códigos comunicativos, algunos muy específicos, como el código gráfico o el de relación compositiva entre los elementos que lo forman. Para leer de forma comprensiva y crítica las imágenes es necesario conocer estos códigos.

Los alumnos pueden leer comprensivamente no solo textos escritos sino también imágenes, viñetas, fotografías. La lectura de imágenes es una actividad muy interesante para practicar con chicos no alfabetizados o que están transitando las primeras etapas de la lectoescritura. Síntesis armónica de dibujo y color, favorecen el vuelo imaginativo y alientan el potencial lector para crear y vivenciar situaciones de diversa índole.

Para leer críticamente las imágenes es importante seguir una serie de pasos: se tiene una visión de conjunto; se analizan los objetos que la componen y su relación interna; se interpreta su significado (teniendo en cuenta que son portadoras de símbolos visuales y de mensajes y pueden generar diferentes significados).

\section{CONCLUSIONES}

Considerando que en la preprueba el 63,2\% se ubica en el nivel C, y 36,8\% se ubican en el nivel B, de la misma forma tenemos que en la postprueba el 68,4\% se ubican en el nivel B y $31,6 \%$ en el nivel A. y el promedio en preprueba $(1,4)$ se diferencia con postprueba $(2,3)$. Se tiene una diferencia considerable entre preprueba y postprueba en cuanto al nivel de consistencia e integración textual en estudiantes del grupo experimental, lo que se justifica como efecto de la aplicación del Programa imágenes visuales del entorno.

Así mismo, en la preprueba el 47,4\% se ubica en el nivel C, y 52,6\% se ubican en el nivel B, de la misma forma tenemos que en la postprueba el $94,7 \%$ se ubican en el nivel B y 
$5,3 \%$ en el nivel A. y el promedio en preprueba $(1,5)$ se diferencia con postprueba $(2,1)$. Se tiene una diferencia considerable entre preprueba y postprueba en cuanto al nivel de organización textual en estudiantes del grupo experimental, lo que se justifica como efecto de la aplicación del Programa imágenes visuales del entorno.

Además, en la preprueba el 73,7\% se ubica en el nivel C, y 26,3\% se ubican en el nivel B, de la misma forma tenemos que en la postprueba el $26,3 \%$ se ubican en el nivel C y $73,7 \%$ en el nivel B. y el promedio en preprueba $(1,3)$ se diferencia con postprueba $(1,7)$. Se tiene una diferencia considerable entre preprueba y postprueba en cuanto al nivel de consistencia e integración textual en estudiantes del grupo experimental, lo que se justifica como efecto de la aplicación del Programa imágenes visuales del entorno

También, en la preprueba el 21,1\% se ubica en el nivel C, y 78,9\% se ubican en el nivel B, de la misma forma tenemos que en la postprueba el 21,1\% se ubican en el nivel B y 78,9\% en el nivel A. y el promedio en preprueba $(1,8)$ se diferencia con postprueba $(2,8)$. Se tiene una diferencia considerable entre preprueba y postprueba en cuanto al nivel de expresividad en estudiantes del grupo experimental, lo que se justifica como efecto de la aplicación del Programa imágenes visuales del entorno.

Así mismo, en la preprueba el 21,1\% se ubica en el nivel C, y 78,9\% se ubican en el nivel B, de la misma forma tenemos que en la postprueba el 84,2\% se ubican en el nivel B y $15,8 \%$ en el nivel A. y el promedio en preprueba $(1,8)$ se diferencia con postprueba $(2,2)$. Se tiene una diferencia considerable entre preprueba y postprueba en cuanto al nivel de consistencia e integración textual en estudiantes del grupo experimental, lo que se justifica como efecto de la aplicación del Programa imágenes visuales del entorno.

Como también, en la preprueba el 78,9\% se ubica en el nivel C, y 21,1\% se ubican en el nivel B, de la misma forma tenemos que en la postprueba el $89,5 \%$ se ubican en el nivel B y $5,3 \%$ en el nivel A. y el promedio en preprueba $(1,2)$ se diferencia con postprueba $(2,0)$. Se tiene una diferencia considerable entre preprueba y postprueba en cuanto al nivel de 
ortografía en estudiantes del grupo experimental, lo que se justifica como efecto de la aplicación del Programa imágenes visuales del entorno.

Finalmente se concluye se tiene que en la preprueba el 10,5\% se ubica en el nivel B, y $89,5 \%$ se ubican en el nivel A, de la misma forma tenemos que en la postprueba el $100 \%$ se ubican en el nivel A. y el promedio en preprueba $(1,9)$ es similar en postprueba $(2,0)$. Se tiene una diferencia considerable entre preprueba y postprueba en cuanto al nivel de caligrafía en estudiantes del grupo experimental, lo que se justifica como efecto de la aplicación del Programa imágenes visuales del entorno.

\section{REFERENCIAS}

Barriga, F. y Hernández, G. (1998) Estrategias docentes para un aprendizaje Significativo. Mexico. Mc Graw Hill.

Gonzales C. (1996). Imagen y sentido. Elementos para una semiótica de los medios visuales. Universidad Nacional Autónoma de México.

Pardo B, Cabrios, Carrión y otros. (1998) Comprensión Lectora. Textos y ayudas figuras. Bs. As. Editorial Plus Ultra

Piaget, J. (1975)"El Nacimiento de la Inteligencia." P g. 250- 260.

Barnerjee, T. y Sothworth, M. (1996). City Sense and City Design Writings and Projects of Kevin Lynch. MIT Press, Cambridge, Massachusetts,

De Gracia, F. (1992) Construir en lo construido. Editorial NEREA, S.A., Madrid,

Febres, B. (1993) Tesis: Bases históricas y morfológicas para un estudio de diseño urbano.

U.C.V. Caracas.

Katz, P. (1994) The New Urbanism. Toward an Architecture of Community. McGraw- Hill, New York.

Hobson, D. (1982) Crossroads: the drama of a soap opera. Londres, Methuen.

Hodge, B. y Tripp, D. (1986) Children and television. Cambridge, Polity Press.

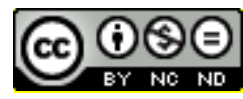

El programa de imágenes visuales del entorno en la producción de textos poéticos (Wilmer Ortega - Chávez) Por Revista Kolpa se encuentra bajo una Licencia Creative Commons-No Comercial-Sin Derivadas 3.0 Uported.

${ }^{\mathrm{a}}$ Wilmer Ortega Chávez, ${ }^{\mathrm{b}}$ Annie Hellen Moreno Modesto y ${ }^{\mathrm{c}}$ Liliam Carola Zevallos Solis Articulo Protegido por Licencia Creative Commons: BY-NC-ND / Protected by Creative Commons: BY-NC-ND. Kolpa es una revista de acceso abierto / Kolpa is an Open Access Journal. 